\title{
Analysis of Torque Maintenance and Fracture Resistance after Fatigue in Retention Screws Made of Different Metals for Screw-Retained Implant-Borne Prosthesis Joints
}

\author{
Maria Beatriz Bello Taborda, ${ }^{1}$ Gabriela Sumie Yaguinuma Gonçalves ${ }^{\mathbb{D}}{ }^{1}$ \\ Cecília Alves de Sousa, ${ }^{1}$ and Wirley Gonçalves Assunção ${ }^{2}$ \\ ${ }^{1}$ Department of Dental Materials and Prosthodontic, Sao Paulo State University (UNESP), Araçatuba, Brazil \\ ${ }^{2}$ Department of Dental Materials and Prosthodontic, São Paulo State University (UNESP), Araçatuba School of Dentistry, \\ São Paulo, Brazil
}

Correspondence should be addressed to Gabriela Sumie Yaguinuma Gonçalves; gabisumie@hotmail.com

Received 18 September 2021; Accepted 18 October 2021; Published 18 November 2021

Academic Editor: Paolo Francesco Manicone

Copyright (C) 2021 Maria Beatriz Bello Taborda et al. This is an open access article distributed under the Creative Commons Attribution License, which permits unrestricted use, distribution, and reproduction in any medium, provided the original work is properly cited.

\begin{abstract}
Purpose. The aim was to evaluate the effect of different metallic alloys used in the manufacture of retention screws for universal cast to long abutment (UCLA) abutments for external hexagon (HE) and Morse taper (MT) connection implants, as well as of mechanical cycling on torque maintenance and fracture resistance through electromechanical fatigue testing by mastication followed by compression testing. Methods. Sixty implants were used, $30 \mathrm{MT}$ and $30 \mathrm{HE}$, with their respective titanium UCLA abutments and retention screws of 5 different materials $(n=6)$ : Ti cp grade 2, Ti cp grade 4 , Ti cp grade 4 hard, Ti grade 5-Ti6Al4V and surgical steel (DSP ${ }^{\circledR}$ Biomedical). The assemblies were positioned in an electromechanical masticatory fatigue testing machine. The fracture strength test was performed by compression testing in a universal testing machine EMICDL-200. Results. The cycled screws and new screws of each alloy group for each connection type were evaluated, obtaining the maximum force (FM), in order to verify the effect of mechanical cycling. The data were tabulated and submitted to appropriate statistical analysis $(\alpha=0.05)$. Conclusion. It was concluded that for the MT, the alloy with the best performance was steel, both in the maintenance of torque and in the compression test, and cycling negatively influenced the maintenance of preload for this connection. The alloy material did not influence torque maintenance for HE. The new screws that were subjected to EMIC showed higher strength. The alloy with the lowest strength was Ti grade 2.
\end{abstract}

\section{Introduction}

Despite being a consolidated technique [1], implant-supported prostheses are still susceptible to biomechanical failures and complications [2,3], more specifically, those that interfere with the stability of the interface region between the implant, abutment, cylinder, and retention screw. As a result, among several complications, loosening of the retention screw may occur, predisposing it to fracture $[2,4,5]$.

The connection between the prosthetic pillar and the implant by means of a retention screw is called screwed connection, and the tightening force exerted on the screw is called torque $[6,7]$. Once applied, it develops a compressive force between the parts that holds the components together, called preload [7]. During the masticatory cycle, there is an incidence of loads on the prosthetic structure, and these external forces, when higher than the preload value, can lead to loosening or even fracture of the screw $[8,9]$.

Analyzing from a mechanical-prosthetic point of view, the main reasons for the fracture of a retention screw are misadjusted infrastructure, occlusal overload, and parafunction $[10,11]$. Therefore, retaining screws are prone to fracture, as it usually occurs after the screw joint is subjected to a long period of stress under multidirectional forces that exceed the preload value, such as premature lateral excursive 
contacts, too tight interproximal contacts, nonpassive fit of restorations, and parafunctional habits $[12,13]$ leading to joint separation, suggesting that a small defect will progressively reach a critical size and cause fracture [14]. Thus, screw loosening and fracture may represent a warning, indicating that too much force and load are being applied to the prosthesis $[15,16]$.

The need to prevent fractures of the retention screw in the screw joint resulted in modifications in properties regarding its design, composition, stem length, body, diameter, number of threads, and different values in the application of torque [17]. In general, it was necessary to evolve the characteristics of the retaining screw to maximize preload and minimize the loss of input torque during thread friction, on the assumption that increasing the stem length helps to achieve optimal elongation and shorter thread lengths reduce friction $[12,18,19]$. Moreover, the most significant factor that gives the screw good qualities is its composition, since the frictional resistance between the implant internal threads and the screw threads, composed of two different metals, can limit the preload leading to fracture [12].

It is essential that the material that composes the retaining screw has properties that, in addition to providing adequate resistance to fracture, favor preload maintenance and support the forces generated by the screw [20]. Most retention screws are made of titanium and its alloys. In a study by Assunção et al. [20], in which a comparison was made between titanium alloy screws (Ti grade 5-Ti6Al4V), gold screws, Ti grade 5 (Ti6Al4V) with diamond surface, and Ti grade 5 (Ti6Al4V) screws with surface treated with aluminum nitride blasting, the group of titanium screws ( $\mathrm{Ti}$ grade $5-\mathrm{Ti} 6 \mathrm{Al} 4 \mathrm{~V})$ showed the highest value of torque maintenance $(81.42 \% \pm 3.57 \%)$.

Titanium alloys are widely used when it comes to implants and their components; however, they present mechanical properties not always favorable. Pure titanium (Ti grade 2 and Ti grade 4), for example, has the disadvantage of low potential mechanical strength and low wear resistance [21], eventhough it is the main material used in implant dentistry. It is the main material used in implant dentistry. Ti6Al4V (Ti grade 5), on the other hand, has good mechanical properties, but may cause toxic effects to patients due to the vanadium and aluminum present in its composition [22]. Grade 4 hard $\mathrm{Ti}$, an alloy modified by a severe plastic deformation method [23], is considered more resistant to compression and fatigue than those conventionally manufactured [24]. As for stainless surgical steel, its main disadvantage is possible corrosion, which is why it is generally used in temporary implants and, nowadays, in miniimplants in orthodontics, as it is biocompatible [25] and has good mechanical properties [26, 27], as well as being resistant, reducing the risk of fracture [28, 29].

Thus, it is valuable for clinicians to understand the mechanical characteristics of materials and the biomechanics of preload and determine the importance of variables that may interfere in this process before applying any external load [30] to achieve a stable abutment-implant junction [31]. Therefore, this study aimed to analyze the complications mentioned above, relating the torque maintenance with the fracture resistance of universal cast to long abutment (UCLA) abutment retention screws made of 4 titanium alloys ( $\mathrm{Ti}$ cp grade $2, \mathrm{Ti}$ cp grade 4 , Ti cp grade 4 hard, and Ti grade 5-Ti6Al4V) and surgical steel for external hexagonal connection and Morse taper implants, submitted to mechanical cycling.

\section{Objectives and Hypothesis}

This research evaluated the effect of 5 different types of metals used in the manufacture of retention screws (Ti cp grade $2, \mathrm{Ti} \mathrm{cp}$ grade $4, \mathrm{Ti} \mathrm{cp}$ grade 4 hard, $\mathrm{Ti}$ grade 5-Ti6Al4V, and surgical steel) of UCLA abutments for external hexagon and Morse taper implants on torque maintenance, before and after electromechanical fatigue testing by mastication, as well as their fracture resistance by compression testing.

The null hypothesis of this study was that the different materials analyzed, the mechanical cycling, and the type of connection would not influence the torque maintenance and the fracture resistance of the retention screws in the different connections.

\section{Materials and Methods}

3.1. Formation of Study Groups. Our study is an in vitro study; it was not used in humans or animals; therefore, it does not fit the EQUATOR guidelines.

Sixty implants were used, 30 with Morse taper connections (MT) and $4.0 \mathrm{~mm}$ platform and 30 with external hexagon (HE) and $4.1 \mathrm{~mm}$ platform and their respective titanium UCLA abutments and retention screws. The screws were made of five different tested materials $(n=6)$, being $\mathrm{Ti}$ cp grade 2, Ti cp grade 4, Ti cp grade 4 hard, Ti grade 5-Ti6Al4V, and surgical steel (DSP ${ }^{\circledR}$ Biomedical, Campo Largo, Paraná, Brazil).

A bipartite metal matrix (Figure 1) was used to position the analogs, allowing a $30^{\circ}$ inclination in relation to the vertical axis (Standard ISSO 14801-2016) [32]. A polyurethane (Polyurethane F160, Axson Brazil, São Paulo, Brazil) was used to embed the implants, as it has uniform elastic properties and a modulus of elasticity close to that of human bone tissue [33]. Once embedded, the implants received the UCLA metal prosthetic abutments, and the retention screw referring to each group and over them a hemispherical device (metal cap), on which loading was given, ensure the application of the load in the longitudinal axis, according to the Technical Standard ISO 14801 of 2016.

\subsection{Torque Application and Measurement of the Remaining} Torque (Destorque). A digital torque meter (torque tool tester, TST series 2 Norbar ${ }^{\circledR}$, Navi Mumbai, India) was used for torque application and assessment of untorque (Figure 2), following a sequence previously established by a randomization process. The torque was applied according to the manufacturer's recommendations, and after a time interval of three minutes, the torque loss was measured $[34,35]$. At this reading, considered as initial torque 

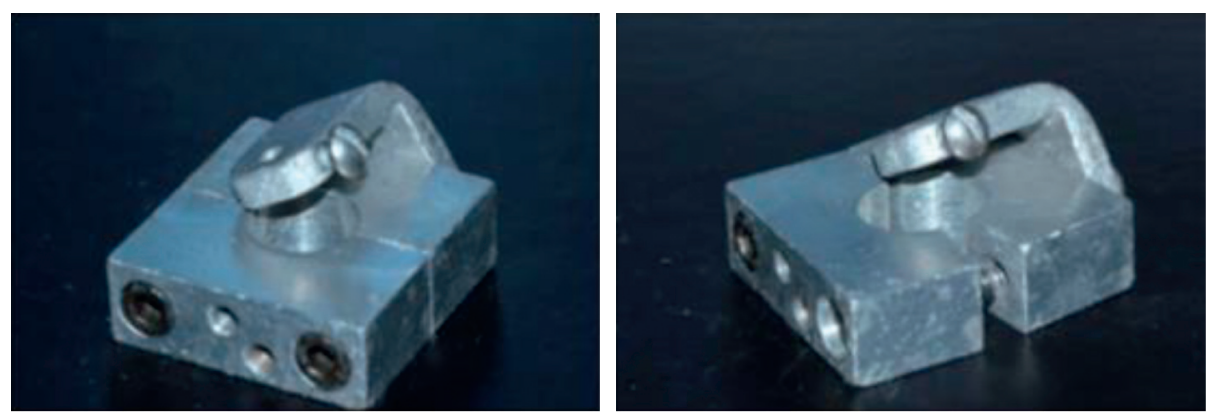

FIgURE 1: Bipartite metallic matrix for embedding of osseointegrated implants.

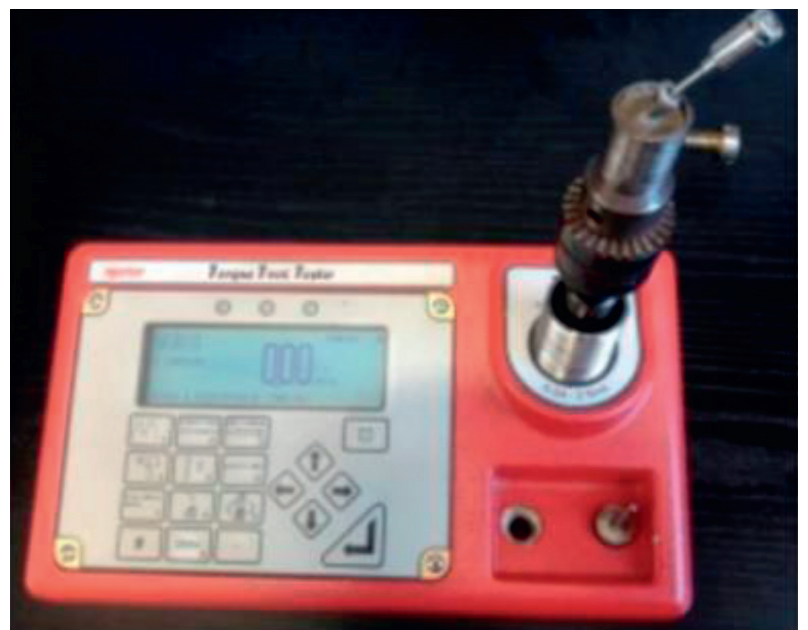

Figure 2: Digital torque gauge (torque tool tester, TST série 2 Norbar $^{\circledR}$, Navi Mumbai, India).

destorque, the remaining torque before mechanical cycling was evaluated. Then, the screws received another torque, called confirmation torque, to be subjected to electromechanical testing of fatigue by mastication, and then, the final torque measurements were taken (postcycling).

3.3. Electromechanical Chewing Fatigue Test. The specimens (implant/abutment/retention screw) were positioned in an electromechanical testing machine of fatigue by mastication (MSFM-ELQUIP, Equipamentos para Pesquisa Odontológica, São Carlos, SP) adjusted to operate in a total of $1 \times 10^{6}$ cycles (or until the occurrence of failure in the specimen), in a frequency of $2 \mathrm{~Hz}$, printing a dynamic oblique load $\left(30^{\circ}\right)$ of $130 \mathrm{~N} \pm 10 \mathrm{~N}$ on each set $[36,37]$. Six specimens were tested at a time, following the same sequence previously established by the randomization process, immersed in distilled water with constant circulation at a temperature of $37^{\circ} \mathrm{C} \pm 2^{\circ} \mathrm{C}$ (Figure 3).

3.4. Mechanical Fracture Toughness Test. The fracture strength test was performed by means of the compression test directly on the retention screws of each screw group for each connection type $(n=6)$ after mechanical cycling, analyzing the maximum force (FM). For this, the screws were fixed in a stainless steel device (Figure 4) and positioned in a



FIgURE 3: Electromechanical mastication fatigue testing equipment.

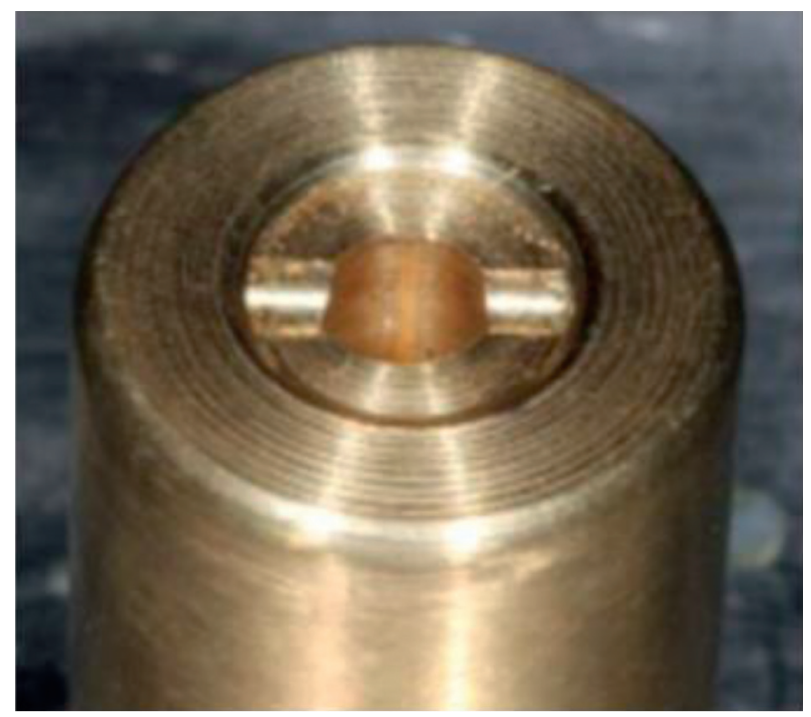

FIGURE 4: Stainless steel device for positioning the retaining screw.

universal testing machine EMIC ${ }^{\circledR D L}$-200 (EMIC equipamentos e sistemas de ensaio LTDA, São José dos Pinhais, PR, Brazil) prepared with a load cell of $2000 \mathrm{~N}$ and axial displacement speed of $0.5 \mathrm{~mm} / \mathrm{min}$ [38] (Figure 5). The loading was transmitted to the screws, in its cervical portion, 



Figure 5: View of the screw positioned in the EMIC with a close-up view of the fracture resistance of the retaining screws.

between the smooth surface and the first thread, by means of a chisel-shaped applicator tip until the screw fracture occurred or until the maximum strain force was exceeded and plastic deformation occurred, with decrease of the resistance force, even without the occurrence of fracture.

3.5. Statistical Planning. The initial and final torque and destorque data, as well as the fracture strength values obtained were tabulated separately.

Statistical analysis was performed using statistical software (Sigma Plot. 12.1, Systat Software Inc., San José, CA, USA). The data were submitted to the Shapiro-Wilk homogeneity test. For torque maintenance analysis, 3-factor ANOVA was used (factors: alloys, connection, and cycling). The Holm-Sidak test was used with the post hoc technique for multiple comparisons at a 5\% significance level. For the fracture strength analysis, a 2-factor ANOVA (factors: alloys and connection) was used, and Tukey's test was used with a post hoc technique for multiple comparisons at a 5\% significance level. For interalloy analysis, one-way ANOVA was used, and the Kruskal-Wallis post hoc test for nonparametric data was used for multiple comparisons at a 5\% significance level.

\section{Results}

4.1. Torque Maintenance. The data obtained regarding the torque maintenance of the retention screws of UCLA abutments, according to the alloys (Ti6Al4V, Ti grade 2, Ti grade 4 , Ti grade 4 hard, and surgical steel), the connection pillar/implant (HE and MT), and time (initial period of application of the insertion torque, initial destorque-precycling, and final destorque-postcycling) were transformed in percentage (\%).

Regarding the alloy factor, regardless of the connections and the period analyzed, the torque loss as a function of the retention screw material did not present a statistically significant difference. When comparing the connection factor independently, in general, it also showed no statistically significant difference, i.e., the connection did not influence the torque values (Table 1 and Figure 6).

Evaluating the connection factors in relation to the different alloys, regardless of the cycling, in general, there was no statistically significant difference, except for the $\mathrm{Ti}$ grade 4 hard ( $p=0.011$ ) for the HE connection, that is, this alloy influenced the value of untorque. Similarly, surgical steel for the MT connection showed a statistically significant difference $(p=0.017)$, demonstrating that it also had a 
TABle 1: Means and standard deviation of torque maintenance (\%) as a function of alloys used, independent of the period.

\begin{tabular}{lcr}
\hline Alloys & Destorque initial & Destorque final \\
\hline Ti6Al4V & $46.79 \pm 10.33^{\mathrm{Aa}}$ & $57.01 \pm 9.35^{\mathrm{Aa}}$ \\
Ti grau 2 & $58.83 \pm 1.50^{\mathrm{Aa}}$ & $47.50 \pm 7.43^{\mathrm{Aa}}$ \\
Ti grau 4 & $57.54 \pm 2.65^{\mathrm{Aa}}$ & $50.45 \pm 20.53^{\mathrm{Aa}}$ \\
Ti grau 4 hard & $52.79 \pm 0.23^{\mathrm{Aa}}$ & $69.89 \pm 31.46^{\mathrm{Ab}}$ \\
Surgical steel & $59.28 \pm 24.53^{\mathrm{Aa}}$ & $70.03 \pm 5.35^{\mathrm{Ab}}$ \\
\hline
\end{tabular}

${ }^{*}$ Distinguished capital letters represent a statistically significant difference in the rows. Distinguished lower case letters represent a statistically significant difference in the columns. Source, prepared by the author.

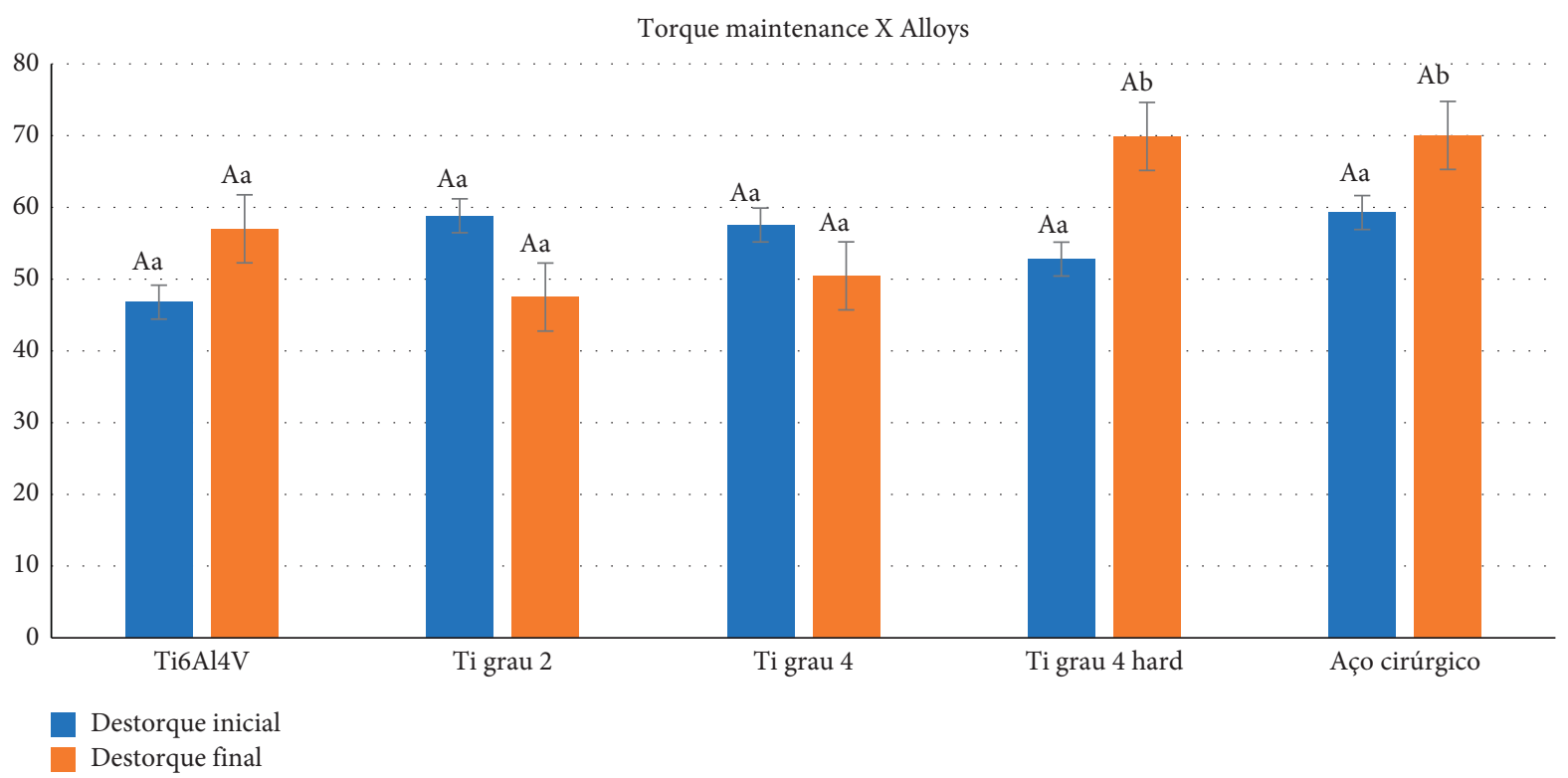

FIGURE 6: Graphical representation of the means and standard deviation of torque maintenance as a function of the alloys used, independent of the period.

positive influence on the destorque value (Table 2 and Figure 7).

Correlating the alloy factors with the connection, in Table 2 and Figure 7, the HE connection did not influence the desorque value, regardless of the alloy type. While for the factors alloys and MT connection, only surgical steel presented a statistically significant difference in relation to the other alloys, showing a mean value of preload maintenance of $73.82 \% \pm 20.69$, contrasting with $35.93 \% \pm 18.78$ and $47.64 \% \pm 22.83$ of the alloys Ti grade $4(p=0.019)$ and ti grade 4 hard $(p=0.041)$, respectively. The other alloys showed no differences among themselves.

Comparing the times used (Table 2 and Figure 7), there was a statistically significant influence on the results of preload maintenance in the initial period of torque application, both in relation to pretorque $(p<0.001)$ and posttorque $(p<0.001)$. Mechanical cycling did not influence the torque values after the confirmation torque was applied, showing no statistically significant difference $(p=0.220)$.

In the comparison between the factors time (precycling and postcycling) and HE connection (Table 3 and Figure 8), there was a significant difference $(p<0.001)$, demonstrating that in this comparison, mechanical cycling had a positive influence on torque maintenance, with an increase of $16.28 \%$ compared to the premechanical cycling value. For the MT connection, comparing the initial torque period $(20 \mathrm{~N})$ with the initial precycling untorque $(60.53 \% \pm 9.64)$ and final postcycling untorque $(52.11 \% \pm 13.75)$ showed a statistically significant difference $(p<0.001)$, representing the loss of torque inserted into the retention screws.

Finally, comparing connection with time, from confirmation torque, given before mechanical cycling, the connection influenced the maintenance of preload, being better for the HE connection $(65.84 \% \pm 17.70)$ in relation to MT (52.11\% \pm 13.75 ), with $p=0.003$ for HE and $p=0.016$ for MT (Table 3 and Figure 8), demonstrating that mechanical cycling negatively influenced the performance of the MT connection.

4.2. Fracture Resistance of the Retaining Screws. 120 retaining screws of the UCLA abutments were submitted to the fracture strength test by the compression test, 60 for HE connection and other 60 for MT connection, of which 30 of each connection were cycled and other 30 were new, noncycled screws. The means and standard deviations were calculated for maximum force (FM) in $\mathrm{kgf}$ (Tables 4 and 5). 
TABLE 2: Means and standard deviation of torque maintenance (destorque) considering HE and MT connections and their respective alloys in the periods premechanical (initial destorque) and postmechanical cycling (final destorque).

\begin{tabular}{lcccc}
\hline Connection & Alloys & Torque initial (N) & Destorque initial (\%) & Destorque final (\%) \\
\hline \multirow{4}{*}{$\mathrm{HE}$} & Ti6Al4V & $30^{\mathrm{Aa}}$ & $39.49 \pm 20.82^{\mathrm{Ba}}$ & $63.63 \pm 18.11^{\mathrm{Ba}}$ \\
& Ti grau 2 & $30^{\mathrm{Aa}}$ & $57.76 \pm 11.74^{\mathrm{Ba}}$ & $42.24 \pm 20.21^{\mathrm{Ba}}$ \\
& Ti grau 4 & $30^{\mathrm{Aa}}$ & $55.66 \pm 23.83^{\mathrm{Ba}}$ & $64.97 \pm 25.91^{\mathrm{Ba}}$ \\
& Ti grau 4 hard & $30^{\mathrm{Aa}}$ & $52.96 \pm 33.44^{\mathrm{Ba}}$ & $92.13 \pm 27.87^{\mathrm{Ba}}$ \\
& Surgical steel & $30^{\mathrm{Aa}}$ & $41.93 \pm 18.07^{\mathrm{Ba}}$ & $66.25 \pm 26.99^{\mathrm{Ba}}$ \\
$\mathrm{MT}$ & Ti6Al4V & $20^{\mathrm{Aa}}$ & $54.10 \pm 26.15^{\mathrm{Ba}}$ & $50.39 \pm 22.25^{\mathrm{Ba}}$ \\
& Ti grau 2 & $20^{\mathrm{Aa}}$ & $59.89 \pm 18.47^{\mathrm{Ba}}$ & $52.76 \pm 18.13^{\mathrm{Ba}}$ \\
& Ti grau 4 & $20^{\mathrm{Aa}}$ & $59.42 \pm 17.04^{\mathrm{Ba}}$ & $35.93 \pm 18.78^{\mathrm{Bb}}$ \\
& Ti grau 4 hard & $20^{\mathrm{Aa}}$ & $52.63 \pm 12.74^{\mathrm{Ba}}$ & $77.64 \pm 22.83^{\mathrm{Bc}}$ \\
& Surgical steel & $20^{\mathrm{Aa}}$ & $76.63 \pm 7.74^{\mathrm{Ba}}$ & $73.82 \pm 20.69^{\mathrm{Bd}}$ \\
\hline
\end{tabular}

*Distinguished capital letters represent a statistically significant difference in the rows. Distinguished lower case letters represent a statistically significant difference in the columns. Source, prepared by the author.

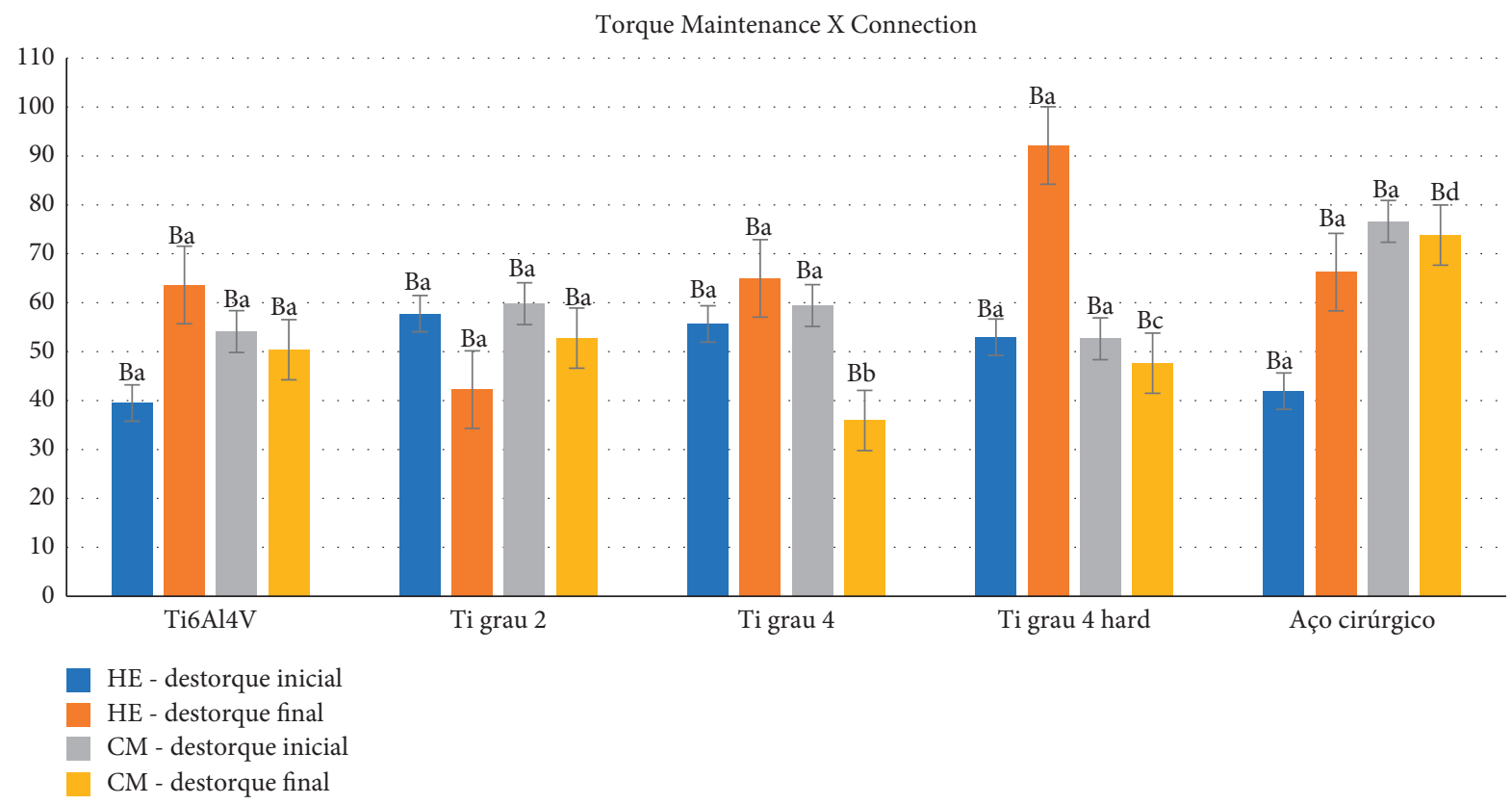

FIgURE 7: Graphical representation of the means and standard deviations of the torque maintenance considering the HE and MT connections and their respective alloys in the premechanical (initial destorque) and postmechanical cycling (final destorque) periods.

TABle 3: Means and standard deviation of the distortions as a function of different connections and periods of distortion (precycling and postcycling), independent of the screw alloys.

\begin{tabular}{lcc}
\hline Connection & External hexagon & Cone morse \\
\hline Destorque initial & $49.56 \pm 8.29^{\mathrm{Aa}}$ & $60.53 \pm 9.54^{\mathrm{Aa}}$ \\
Destorque final & $65.84 \pm 17.70^{\mathrm{Bb}}$ & $52.11 \pm 13.75^{\mathrm{Bc}}$ \\
\hline
\end{tabular}

*Distinguished capital letters represent a statistically significant difference in the rows. Distinguished lower case letters represent a statistically significant difference in the columns. Source, prepared by the author.

Analyzing the prosthetic connections according to the alloys (Table 4 and Figure 9), the behavior of the alloys new surgical steel $(p=0.002)$ and Ti grade 4 hard $(p=0.008)$ influenced the connection performance, showing better results when in the MT connection, with means of $75.68 \mathrm{kgf} \pm 7.25$ and $51.05 \mathrm{kgf} \pm 5.31$. Besides them, Ti6Al4V, regardless of being cycled or new, also showed good results $(p<0.001)$ for the MT connection, with averages $57.54 \mathrm{kgf} \pm 6.16$ and $57.86 \mathrm{kgf} \pm 3.18$, respectively. While the surgical steel cycled screws, new and cycled Ti grade 4 , and new and cycled Ti grade 2 screws were not influenced by the connection $(p>0.05)$, they did not present a statistically significant difference.

Correlating the factors alloy and connection, for the HE connection, screws made of surgical steel, regardless of being cycled or not, presented the best performance for this connection, with FM values of $70.82 \mathrm{kgf} \pm 7.23$ and $65.94 \mathrm{kgf} \pm 9.11$, with a statistically significant difference $(p<0.005)$ in relation to all other alloys, except among themselves $(p=0.849)$. Besides the steel screws, the new and cycled screws of Ti alloy grade 4 hard $(43.59 \mathrm{kgf} \pm 2.41$ and $42.81 \mathrm{kgf} \pm 1.72$, respectively) also showed a statistically significant difference, being superior when compared to the Ti alloy grade 2 screws $(32.52 \mathrm{kgf} \pm 5.49)$, with $p<0.005$. 


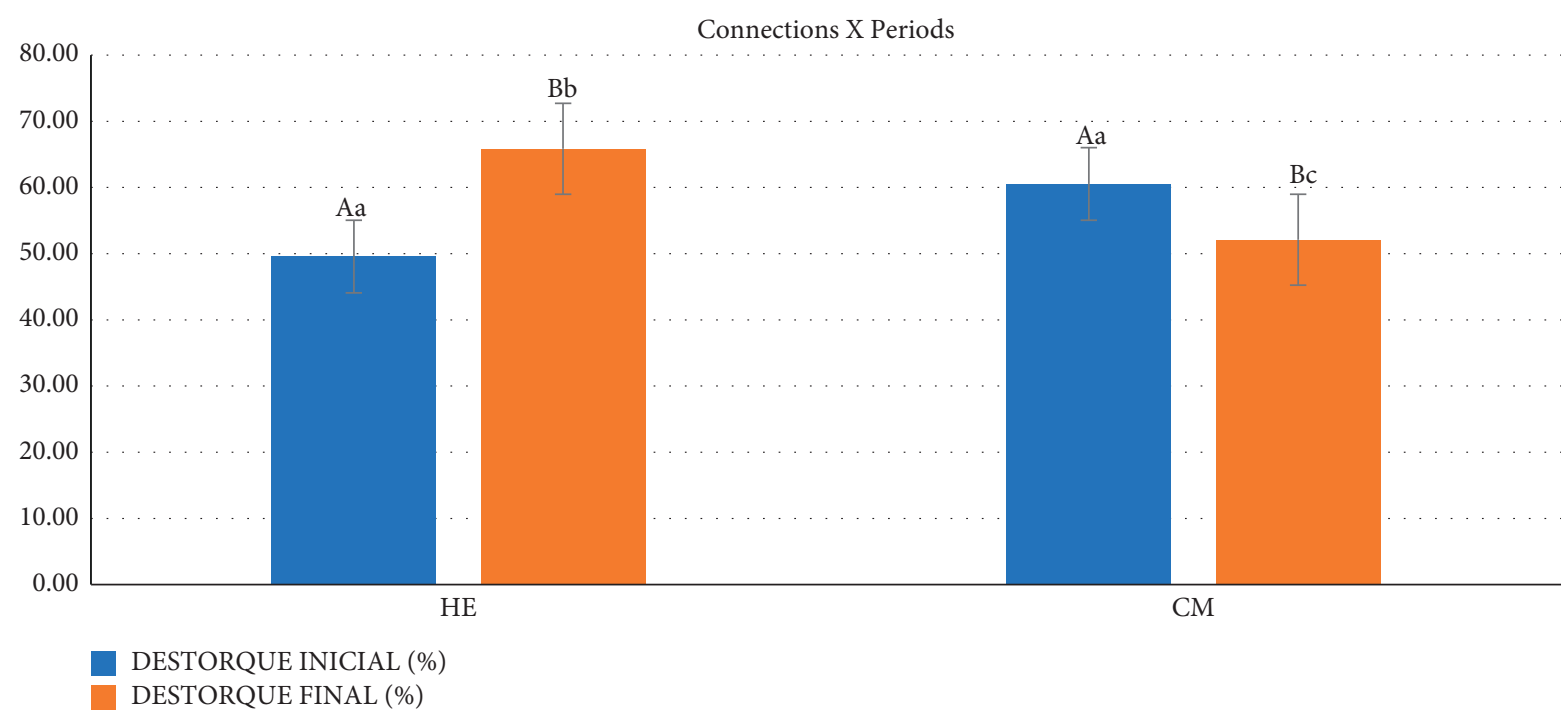

FIGURE 8: Graphical representation of the averages and standard deviation of the connections in relation to the analyzed untorque periods.

TABLE 4: Means and standard deviations for maximum force (kgf) as a function of alloy type for HE and MT fittings.

\begin{tabular}{lcc}
\hline Connections & Alloys & Maximum force (kgf) \\
\hline \multirow{4}{*}{ Ti6Al4V } & $40.01 \pm 1.22^{\mathrm{Aa}}$ \\
Ti grau 2 & $32.52 \pm 5.49^{\mathrm{Aa}}$ \\
Ti grau 4 & $41.25 \pm 2.96^{\mathrm{Aa}}$ \\
& Ti grau 4 hard & $42.81 \pm 1.72^{\mathrm{Ba}}$ \\
& Surgical steel & $70.82 \pm 7.23^{\mathrm{Ca}}$ \\
Ti6Al4V novo & $40.59 \pm 1.60^{\mathrm{Aa}}$ \\
Ti grau 2 novo & $35.01 \pm 6.24^{\mathrm{Aa}}$ \\
Ti grau 4 novo & $38.66 \pm 1.78^{\mathrm{Aa}}$ \\
& Ti grau 4 hard novo & $43.59 \pm 2.41^{\mathrm{Ba}}$ \\
New surgical steel & $65.94 \pm 9.11^{\mathrm{Ca}}$ \\
Ti6Al4V & $57.54 \pm 6.16^{\mathrm{Aa}}$ \\
Ti grau 2 & $28.55 \pm 1.44^{\mathrm{Ba}}$ \\
Ti grau 4 & $43.27 \pm 1.65^{\mathrm{Ca}}$ \\
Ti grau 4 hard & $51.05 \pm 5.31^{\mathrm{Ba}}$ \\
Surgical steel & $73.05 \pm 8.54^{\mathrm{Da}}$ \\
& Ti6Al4V novo & $57.86 \pm 3.18^{\mathrm{Ea}}$ \\
Ti grau 2 novo & $31.58 \pm 6.68^{\mathrm{Fa}}$ \\
Ti grau 4 novo & $43.53 \pm 8.30^{\mathrm{Ga}}$ \\
& Ti grau 4 hard novo & $49.12 \pm 3.62^{\mathrm{Ha}}$ \\
New surgical steel & $75.68 \pm 7.25^{\mathrm{Ia}}$ \\
\hline
\end{tabular}

${ }^{*}$ Distinguished capital letters in the rows indicate a statistically significant difference. Distinguished lower case letters in the columns represent a statistically significant difference. Source, prepared by the author.

For the MT connection in function of the alloys, the new surgical steel screws with FM of $75.68 \mathrm{kgf} \pm 7.25$ and cycled of $73.05 \mathrm{kgf} \pm 8.54$ also presented the best performance, with a statistically significant difference for all other alloys, $p<0.001$, except among themselves, $p=0.997$. It was also possible to observe that the cycled screws of Ti6Al4V $(57.54 \mathrm{kgf} \pm 6.16)$ and new $(57.86 \mathrm{kgf} \pm 3.18)$, when compared to the screws of Ti grade 2 and Ti grade 4, regardless of being cycled or new, were superior to the other alloys, demonstrating that there is a statistically significant difference in the choice between these alloys $(p<0.005)$, in which the alloy with the worst performance was Ti grade 2 . When
TABle 5: Means and standard deviations for maximum force (kgf) as a function of alloy type and aging (new and cycled), independent of connection type.

\begin{tabular}{lc}
\hline Alloys & Maximum force (kgf) \\
\hline Ti6Al4V cycled & $48.77 \pm 12.40^{\mathrm{A}}$ \\
Ti6Al4V new & $49.23 \pm 12.21^{\mathrm{A}}$ \\
Ti grau 2 cycled & $30.53 \pm 2.80^{\mathrm{B}}$ \\
Ti grau 2 new & $33.29 \pm 2.42^{\mathrm{C}}$ \\
Ti grau 4 cycled & $42.26 \pm 1.42^{\mathrm{D}}$ \\
Ti grau 4 new & $41.09 \pm 3.44^{\mathrm{D}}$ \\
Ti grau 4 hard cycled & $46.93 \pm 5.82^{\mathrm{E}}$ \\
Ti grau 4 hard new & $46.35 \pm 3.90^{\mathrm{E}}$ \\
Cycled surgical steel & $71.93 \pm 1.57^{\mathrm{E}}$ \\
New surgical steel & $70.81 \pm 6.89^{\mathrm{E}}$ \\
\hline
\end{tabular}

*Distinct capital letters in the column represent statistically significant difference. Source, prepared by the author.

the screws of these alloys were cycled, they presented an FM value of $28.55 \mathrm{kgf} \pm 1.44$.

Finally, when analyzing the FM of different alloy screws, independent of the type of connection, but dependent on aging (new or mechanically cycled screws) (Table 5 and Figure 10), the alloys with the best performances, which showed no statistically significant difference $(p>0.005)$, were surgical steel in cycled screws, surgical steel in new screws, Ti grade 4 hard in cycled and new screws, and Ti6Al4V in new screws.

\section{Discussion}

According to the observed results, the null hypothesis was rejected; on the type of alloy used in the manufacturing of retaining screws, the mechanical cycling and the type of connection influenced the torque maintenance and the fracture resistance of the screws.

Metals can be hot-formed or cold-formed [39]. Whenever they are submitted to plastic deformation, internal defects are generated in their microstructure favoring 


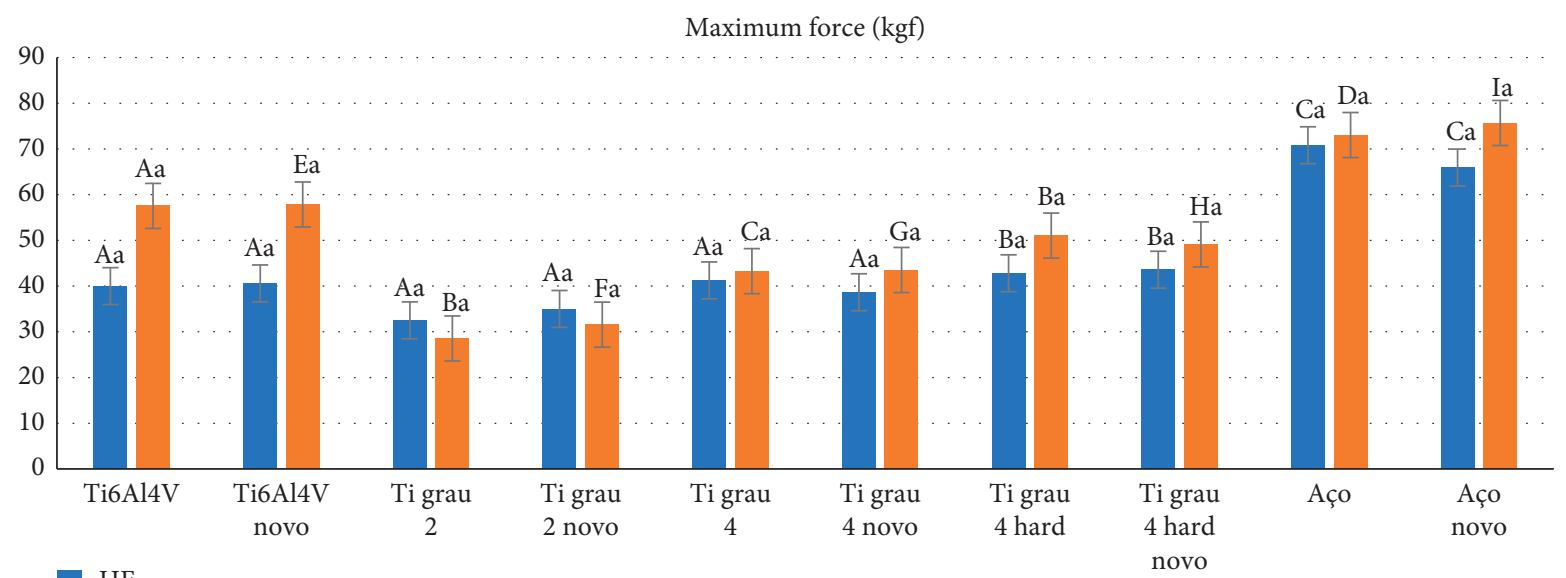

HE

FIgUre 9: Graphical representation of the means and standard deviations for maximum force (kgf) as a function of alloy type for HE and MT connections.

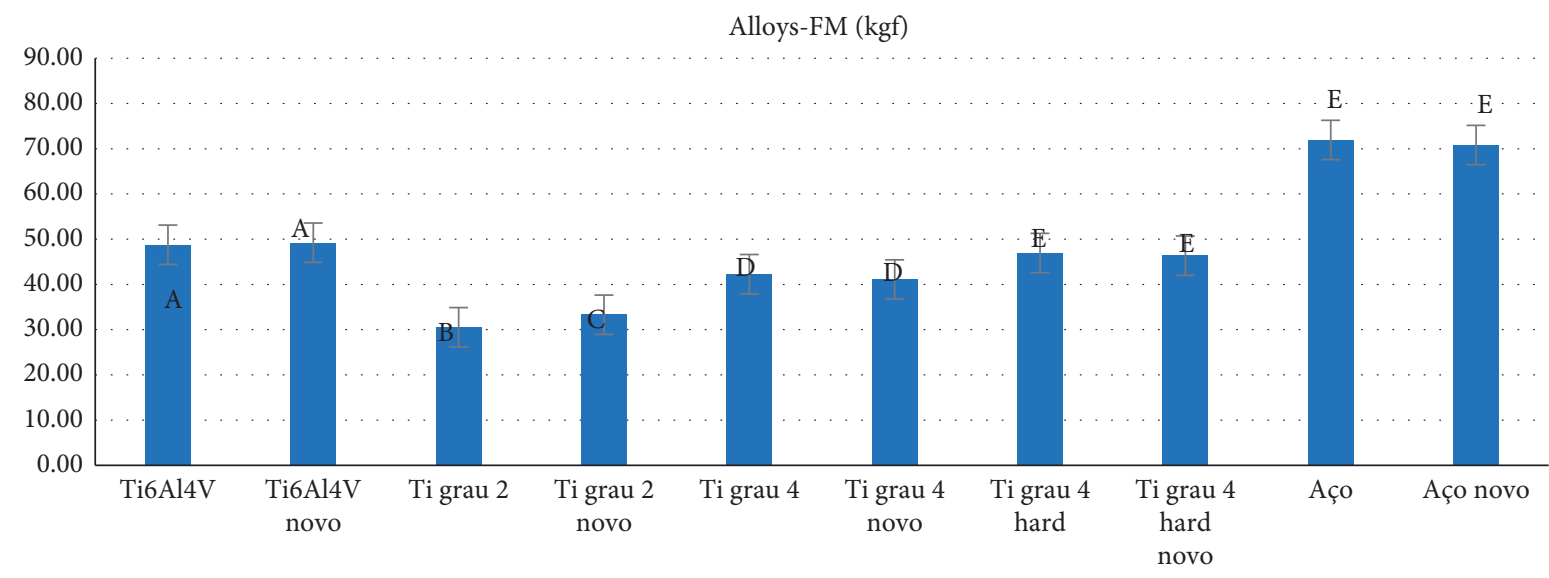

FiguRE 10: Graphical representation of the means and standard deviations for maximum force (kgf) as a function of the type of metal alloy and its aging (new and cycled), independent of the type of connection.

their mechanical resistance. When the deformation is performed hot, the thermal energy causes the defects created during the process to be eliminated, and the hardening of the metal does not occur. In plastic deformation at low temperatures (cold deformation), the defects generated in the internal microstructure remain stored, consequently increasing the mechanical resistance.

The higher values of destorque (higher preload maintenance) and fracture resistance indicate superiority of surgical steel alloy in relation to Ti alloy grade 4 hard and $\mathrm{Ti}$ alloy grade 4 , respectively, and especially compared to other alloys.

The use of stainless steels in the manufacture of biomaterials has been widely used until today. Its use is justified mainly by the combination of properties such as good acceptance by the organism, low cost, good formability, high mechanical resistance, and reasonable resistance to corrosion $[40,41]$. The higher strength of steel is attributed mainly to the combination of nitrogen and niobium added to its composition during cold forming. These additions promote the hardening of its particles during the steel's recrystallization process [42]. Moreover, nitrogen favors its process during plastic deformation, which ensures its good mechanical resistance [43].

Regarding the metallic alloys, the Ti alloy grade 4 hard showed influence on the destorque value in this study, presenting good results for the retaining screws. This result corroborates the study by Elias and coworkers [44] who after mechanical evaluations of $\mathrm{Ti}$ alloys grade 2 , Ti6Al4V, Ti grade 4 , and grade 4 hard involving tension, compression, hardness, and torque tests, the Ti alloy grade 4 hard showed superior mechanical strength, as well as in the present study, revealing an improvement in the mechanical properties of this material. Another result published by the same authors, which is in agreement with the present study, is that when comparing the alloys in the compression test, Ti grade 4 hard presented the highest result when compared to Ti grades 2 and 4, remaining close to Ti6Al4V.

In plastic deformation at low temperatures (cold), the defects generated in the internal microstructure remain 
stored, consequently increasing the mechanical strength. This phenomenon is called strain hardening. From this mechanism can be obtained the hardened Ti grade 4, also called Ti cp4 hard, whose chemical composition is identical to Ti grade $4[39,44]$. This alloy, recently used for dental implants, has shown higher mechanical strength than the other alloys (Ti cp and Ti6Al4V) [45].

Although Ti6Al4V showed satisfactory results in this study [46], two clinical cases of reactive lesions in the periimplant mucosa were reported, which were diagnosed as pyogenic granuloma and peripheral giant cell granuloma. In histopathological analysis, they observed vascular proliferation, intense inflammatory infiltrate, and metal-like particles. They suggested that these fragments were $\mathrm{Ti}$ ions released into the periimplant mucosa due to the corrosive process of the implant's prosthetic platform surface [46, 47]. Among the ions released by Ti6Al4V alloy, vanadium (V) is considered a highly cytotoxic metal and a cause of foreign body reaction [48], and aluminum ( $\mathrm{Al}$ ) is related to neurological disorders, such as Alzheimer's disease [49]. Thus, eventhough its mechanical properties are excellent, its biocompatibility is under suspicion, and its use is not the first-choice indication for implants and their prosthetic components.

When analyzing the type of prosthetic connection with mechanical cycling, according to some studies $[8,50]$, the Morse taper was considered a mechanically superior connection to the external hexagon. However, in this study, the external hexagon was the one that showed better postcycling torque maintenance, unlike the Morse taper, which showed a statistically significant negative difference between precycling (after confirmation torque) and postmechanical cycling (final torque) periods. Corroborating with this research, some studies have also demonstrated that HE showed better torque maintenance compared to retention screws [51,52], and for Kim and collaborators [52], the loss of preload, after mechanical cycling, depends specifically on the type of abutment and the characteristics of the abutment/implant connection design, besides the wider implant diameter being more advantageous in relation to torque loss [17].

In the literature review [53], even with the consensus established by several authors that the internal connection associated with the MT is the most fatigue-resistant type of connection, screw loosening is considered a multifactorial event that depends not only on the type of connection but also on the design and material of making the retention screw, type and design of the prosthetic abutments, direction of occlusal forces, and premature contact points among other factors.

For other authors [54], untorque values close to or greater than the applied insertion torque indicate a good prognosis for the connections in question, as occurred with the external hexagon connection in this study. The superiority of the hexagon may also mean that this connection has undergone mechanical transformations, conferring improvements in the material and, consequently, demonstrating good performance, related to the type of raw material and manufacturing quality, which differ between manufacturers.
As shown in this study, the lower torque maintenance for the Morse taper, which has an internal connection, is similar to the research of Lee and colleagues [55] and others [17, 55], when they stated that in the external hexagonal implant system, because they have greater thickness in their lateral walls, they are more resistant to compressive forces during the reception of occlusal loads, leading to a lower axial displacement of the abutment on the implant $[56,57]$. This displacement can cause biomechanical complications such as loosening of the retention screw, leading to prosthetic instability and maladjustment, which justifies the lower torque maintenance in Morse tapers observed in this study.

In this study, the confirmation torque influenced the torque values. This fact can also be observed in other studies $[58,59]$, which showed a progressive decrease in the torque value. In this study, it was $55.04 \%$, regardless of the connection, after application of the insertion torque. When the initial torque is applied, it is lost even when the screwed joint is not subjected to the application of any external force [60]. This can be explained by the accommodation or inclusion relaxation of the retaining screw in the abutment/implant connection, called the sedimentation effect [61]. To prevent this decrease in insertion torque, some manufacturers recommend retightening the screw after 10 minutes [62]. In this study, the confirming torque was applied 3 minutes after the initial torque, with satisfactory results.

In the fracture resistance test, 60 new screws of the two connections were submitted, in addition to the screws that had already been submitted to mechanical cycling. In general, the new screws had the best results of maximum strength, which indicates that they resisted more to the forces on them before failure, which may indicate that mechanical cycling changes the capacity of the retention screws to resist to external forces and may lead to their fracture in the long term.

When comparing the prosthetic connections, the screws from the Morse taper connection showed the highest means of maximum force, although very close to the HE means. For this connection, the new screws were also superior to the cycled ones, but with very close values, demonstrating their biomechanical stability.

Regarding the metallic alloys used during the compression test, the ones that showed better mechanical performance were the surgical steel alloy, followed by the alloy Ti grade 4 hard and Ti grade 4 . Surgical steel, despite its high strength, still presents corrosive characteristics [41, 45]. The hard Ti grade 4 alloy, for Elias $\mathrm{CN}$ and collaborators, after being submitted to severe plastic deformation, became more resistant to compression than the conventionally made alloy [24]. The worst performance was demonstrated by the Ti grade 2 alloy, which, as previously mentioned, presents low potential mechanical strength and low wear resistance, inhibiting its use for biomedical applications [24], in addition to improving its mechanical properties hampered by the possible reduction of its biocompatibility [21].

The relevance of this study lies in the fact that it demonstrates clinical situations, in which this "in vitro" research simulated occlusal forces for the stability of the screwed connection with retention screws of different metallic alloys 
of UCLA abutments, in which the screws were submitted to the torque recommended by the manufacturer. Since the torque applied tends to decrease with time, it is essential to perform periodic evaluations to maintain an adequate torque, thus avoiding loosening and, consequently, fracture of the retention screws of the screwed junctions.

The range of potential sources of bias as this is an in vitro assay limits the full representation of the results as it does not show the response of a living being/tissue to a material/drug; it is merely a control and a baseline for the next stage of development. So, more needed is long-term randomized clinical trials to establish a real approach to this approach for future clinical practice.

\section{Conclusion}

The different associated materials, a mechanical cycling, and the type of connection did not influence the maintenance of torque and fracture resistance of the retention screws in different exclusives.

Based on the results obtained and within the methodological limitations of this in vitro study, we can conclude the following:

(i) For the MT connection, the alloys that showed the best performance in maintaining torque were surgical steel, Ti grade 4 hard, and Ti grade 4

(ii) Mechanical cycling negatively influenced torque maintenance for this connection

(iii) The compression test showed that new screws have higher fracture resistance, suggesting the periodic replacement of the retaining screws in use

(iv) The metallic alloys influenced the mechanical resistance of the retention screws, being the surgical steel the most resistant and the Ti grade 2 alloy the least resistant, differently from the torque maintenance, in which the alloys, when analyzed independently, presented similar behavior

\section{Data Availability}

The data that support the findings of this study are available in the supplementary material of this article.

\section{Conflicts of Interest}

The authors declare that they have no conflicts of interest.

\section{Authors' Contributions}

W.G.A. and M.B.B.T. conceived the ideas; M.B.B.T and C.A.S collected and analyzed the data; and M.B.B.T and G.S.Y.G led the writing.

\section{Acknowledgments}

This work was supported by the Programa Institucional de Bolsas de Iniciação Científica (PIBIC) (157953/2017-3).

\section{References}

[1] S. G. Kourtis, S. Sotiriadou, S. Voliotis, and A. Challas, "Private practice results of dental implants. Part I: survival and evaluation of risk factors-part II: surgical and prosthetic complications," Implant Dentistry, vol. 13, no. 4, pp. 373-385, 2004.

[2] C. Sahin and S. Ayyildiz, "Correlation between microleakage and screw loosening at implant-abutment connection," The Journal of Advanced Prosthodontics, vol. 6, no. 1, pp. 35-38, 2014.

[3] A. Theoharidou, H. P. Petridis, K. Tzannas, and P. Garefis, "Abutment screw loosening in single-implant restorations: a systematic review," The International Journal of Oral \& Maxillofacial Implants, vol. 23, no. 4, pp. 681-690, 2008.

[4] C. J. Goodacre, J. Y. K. Kan, and K. Rungcharassaeng, "Clinical complications of osseointegrated implants," The Journal of Prosthetic Dentistry, vol. 81, no. 5, pp. 537-552, 1999.

[5] M. S. Schwarz, "Mechanical complications of dental implants," Clinical Oral Implants Research, vol. 11, no. 1, pp. 156-158, 2000.

[6] E. A. McGlumphy, D. A. Mendel, and J. A. Holloway, "Implant screw mechanics," Dental Clinics of North America, vol. 42, no. 1, pp. 71-89, 1998.

[7] D. Byrne, S. Jacobs, B. O'Connell, F. Houston, and N. Claffey, "Preloads generated with repeated tightening in three types of screws used in dental implant assemblies," Journal of Prosthodontics, vol. 15, no. 3, pp. 164-171, 2006.

[8] K. X. Michalakis, P. Calvani, S. Muftu, A. Pissiotis, and H. Hirayama, "The effect of different implant-abutment connections on screw joint stability," Journal of Oral Implantology, vol. 40, no. 2, pp. 146-152, 2014.

[9] N. Sesma, C. Pannuti, and G. Cardaropoli, "Retrospective clinical study of 988 dual acid-etched implants placed in grafted and native bone for single-tooth replacement," The International Journal of Oral \& Maxillofacial Implants, vol. 27, no. 5, pp. 1243-1248, 2012.

[10] R. Mericske-Stern, A. H. Geering, W. B. Burgin, and H. Graf, "Three-dimensional force measurements on mandibular implants supporting overdentures," The International Journal of Oral \& Maxillofacial Implants, vol. 7, no. 2, pp. 185-194, 1992.

[11] S. Luterbacher, I. Fourmousis, N. P. Lang, and U. Brägger, "Fractured prosthetic abutments in osseointegrated implants: a technical complication to cope with," Clinical Oral Implants Research, vol. 11, no. 2, pp. 163-170, 2000.

[12] P. P. Binon, "Implants and components: entering the new millennium," The International Journal of Oral \& Maxillofacial Implants, vol. 15, no. 1, pp. 76-94, 2000.

[13] H. H. Mohammed, J.-H. Lee, J.-M. Bae, and H.-W. Cho, "Effect of abutment screw length and cyclic loading on removal torque in external and internal hex implants," The Journal of Advanced Prosthodontics, vol. 8, no. 1, pp. 62-69, 2016.

[14] H. W. Wiskott, J. I. Nicholls, and U. C. Belser, "Stress fatigue: basic principles and prosthodontic implications," The International Journal of Prosthodontics, vol. 8, no. 2, pp. 105-116, 1995.

[15] W. G. Assunção, V. A. R. Barão, J. A. Delben, É. A. Gomes, and I. R. Garcia Jr., "Effect of unilateral misfit on preload of retention screws of implant-supported prostheses submitted to mechanical cycling," Journal of Prosthodontic Research, vol. 55, no. 1, pp. 12-18, 2011. 
[16] W. G. Assunção, J. A. Delben, L. F. Tabata, R. Barao, V. Adelino, and A. Gomes, "Effect of vertical misfit on screw joint stability of implant-supported crowns," Journal of Materials Engineering and Performance, vol. 20, no. 6, p. 947, 2011.

[17] H.-M. Shin, J.-B. Huh, M.-J. Yun, Y.-C. Jeon, B. M. Chang, and C.-M. Jeong, "Influence of the implant-abutment connection design and diameter on the screw joint stability," The Journal of Advanced Prosthodontics, vol. 6, no. 2, pp. 126-132, 2014.

[18] K. Arvidson, H. Bystedt, and I. Ericsson, "Histometric and ultrastructural studies of tissues surrounding Astra dental implants in dogs," The International Journal of Oral \& Maxillofacial Implants, vol. 5, no. 2, pp. 127-134, 1990.

[19] P. P. Binon, "The spline implant: design, engineering, and evaluation," The International Journal of Prosthodontics, vol. 9, no. 5, pp. 419-433, 1996.

[20] W. G. Assunção, J. A. Delben, L. F. Tabata, V. A. R. Barão, É. A. Gomes, and I. R. Garcia Jr., "Preload evaluation of different screws in external hexagon joint," Implant Dentistry, vol. 21, no. 1, pp. 46-50, 2012.

[21] M. Niinomi, "Mechanical biocompatibilities of titanium alloys for biomedical applications," Journal of the Mechanical Behavior of Biomedical Materials, vol. 1, no. 1, pp. 30-42, 2008.

[22] L. Morais, G. Serra, C. Muller et al., "Titanium alloy miniimplants for orthodontic anchorage: immediate loading and metal ion release," Acta Biomaterialia, vol. 3, no. 3, pp. 331-339, 2007.

[23] R. Z. Valiev, R. K. Islamgaliev, and I. V. Alexandrov, "Bulk nanostructured materials from severe plastic deformation," Progress in Materials Science, vol. 45, no. 2, pp. 103-189, 2000.

[24] C. N. Elias, D. J. Fernandes, F. M. Souza, E. De Monteiro, and R. S. Biasi, "Mechanical and clinical properties of titanium and titanium-based alloys (Ti G2, Ti G4 cold worked nanostructured and Ti G5) for biomedical applications," Journal of Materials Research and Technology, vol. 30, no. 10, pp. 1-10, 2018.

[25] M. A. Cornelis, N. R. Scheffler, H. J. De Clerck, J. F. C. Tulloch, and C. N. Behets, "Systematic review of the experimental use of temporary skeletal anchorage devices in orthodontics," American Journal of Orthodontics and Dentofacial Orthopedics, vol. 131, no. 4, pp. S52-S58, 2007.

[26] P. H. Buschang, R. Carrillo, B. Ozenbaugh, and P. E. Rossouw, "2008 survey of AAO members on miniscrew usage," Journal of Clinical Orthodontics, vol. 42, no. 9, pp. 513-518, 2008.

[27] D. Francioli, G. Ruggiero, and R. Giorgetti, "Mechanical properties evaluation of an orthodontic miniscrew system for skeletal anchorage," Progress in Orthodontics, vol. 11, no. 2, pp. 98-104, 2010.

[28] R. N. Brown, B. E. Sexton, T.-M. Gabriel Chu et al., "Comparison of stainless steel and titanium alloy orthodontic miniscrew implants: a mechanical and histologic analysis," American Journal of Orthodontics and Dentofacial Orthopedics, vol. 145, no. 4, pp. 496-504, 2014.

[29] A. Carano, P. Lonardo, S. Velo, and C. Incorvati, "Mechanical properties of three different commercially available miniscrews for skeletal anchorage," Progress in Orthodontics, vol. 6, no. 1, pp. 82-97, 2005.

[30] T. Guda, T. A. Ross, L. A. Lang, and H. R. Millwater, "Probabilistic analysis of preload in the abutment screw of a dental implant complex," The Journal of Prosthetic Dentistry, vol. 100, no. 3, pp. 183-193, 2008.

[31] L. A. Lang, B. Kang, R.-F. Wang, and B. R. Lang, "Finite element analysis to determine implant preload," The Journal of Prosthetic Dentistry, vol. 90, no. 6, pp. 539-546, 2003.
[32] ISO, ISO 14801-Dentistry Implants Dynamic Loading Fatigue Test for Endousseous Dental Implants, ISO, Geneva, Switzerland, 2016.

[33] R. W. Hergenrother, H. D. Wabers, and S. L. Cooper, "Effect of hard segment chemistry and strain on the stability of polyurethanes: in vivo biostability," Biomaterials, vol. 14, no. 6, pp. 449-458, 1993.

[34] J. A. Delben, V. A. R. Barão, P. H. Dos Santos, and W. G. Assunção, "Influence of abutment type and esthetic veneering on preload maintenance of abutment screw of implant-supported crowns," Journal of Prosthodontics, vol. 23, no. 2, pp. 134-139, 2014.

[35] A. Ortorp, T. Jemt, A. Wennerberg, C. Berggren, and M. Brycke, "Screw preloads and measurements of surface roughness in screw joints: an in vitro study on implant frameworks," Clinical Implant Dentistry and Related Research, vol. 7, no. 3, pp. 141-149, 2005.

[36] C. de Assis Vianna, J. Aparecida Delben, V. A. R. Barão, M. Barbosa Ferreira, P. Henrique dos Santos, and W. Goncalves Assuncao, "Torque stability of different abutment screws submitted to mechanical cycling," The International Journal of Oral \& Maxillofacial Implants, vol. 28, no. 5, pp. e209-e214, 2013.

[37] J. R. P. Jorge, V. A. R. Barao, J. A. Delben, and W. G. Assuncao, "The role of implant/abutment system on torque maintenance of retention screws and vertical misfit of implant-supported crowns before and after mechanical cycling," The International Journal of Oral \& Maxillofacial Implants, vol. 28, no. 2, pp. 415-422, 2013.

[38] F. P. Nothdurft, K. Neumann, and A. W. Knauber, "Fracture behavior of zirconia implant abutments is influenced by superstructure-geometry," Clinical Oral Investigations, vol. 18, no. 5, pp. 1467-1472, 2014.

[39] C. N. Elias, J. Roestel, M. A. Zucareli, C. Campaneri, and C. R. S. Resende, "Implantes de titânio comercialmente puro com alta resistência mecânica para aplicações em odontologia," ImplantNews, vol. 10, no. 6, pp. 74-81, 2013.

[40] E. J. Giordani, "Propriedades e mecanismos de nucleação de trincas por fadiga em meio neutro e meio fisiológico artificial de dois aços inoxidáveis austeníticos utilizados como biomateriais," Doctoral thesis, Faculdade de Engenharia Mecânica, Universidade Estadual de Campinas, Campinas, Brazil, 2001.

[41] R. F. V. Villamil, M. L. C. A. Afonso, S. O. Rogero, C. A. Barbosa, A. Sokolowski, and S. M. L. Agostinho, "Comparative electrochemical studies of ISO 5832-9 stainless steels at different media of biological interest," Revista Escola de Minas, vol. 63, no. 1, 2010.

[42] M. Nyström, U. Lindstedt, B. Karlsson, and J. Nilsson, "Influence of nitrogen and grain size on deformation behaviour of austenitic stainless steel," Materials Science and Technology, vol. 13 , no. 7, pp. 560-567, 1997.

[43] R. E. Stoltz and J. B. Sande, "The effect of nitrogen on stacking fault energy of Fe-Ni-Cr-Mn steels," Metallurgical Transactions A, vol. 11, no. 6, pp. 1033-1037, 1980.

[44] C. N. Elias, D. J. Fernandes, C. R. S. Resende, and J. Roestel, "Mechanical properties, surface morphology and stability of a modified commercially pure high strength titanium alloy for dental implants," Dental Materials, vol. 31, no. 2, pp. e1-e13, 2015.

[45] X. Tang, S. Wang, L. Qian et al., "Corrosion behavior of nickel base alloys, stainless steel and titanium alloy in supercritical water containing chloride, phosphate and oxygen," Chemical Engineering Research and Design, vol. 100, pp. 530-541, 2015. 
[46] D. G. Olmedo, M. L. Paparella, D. Brandizzi, and R. L. Cabrini, "Reactive lesions of peri-implant mucosa associated with titanium dental implants: a report of 2 cases," International Journal of Oral and Maxillofacial Surgery, vol. 39, no. 5, pp. 503-507, 2010.

[47] D. G. Olmedo, M. L. Paparella, M. Spielberg, D. Brandizzi, M. B. Guglielmotti, and R. L. Cabrini, "Oral mucosa tissue response to titanium cover screws," Journal of Periodontology, vol. 83, no. 8, pp. 973-980, 2012.

[48] P. G. Laing, A. B. Ferguson Jr., and E. S. Hodge, "Tissue reaction in rabbit muscle exposed to metallic implants," Journal of Biomedical Materials Research, vol. 1, no. 1, pp. 135-149, 1967.

[49] A. Mirza, A. King, C. Troakes, and C. Exley, "Aluminium in brain tissue in familial Alzheimer's disease," Journal of Trace Elements in Medicine and Biology, vol. 40, pp. 30-36, 2017.

[50] M. S. Pita, R. B. Anchieta, V. A. R. Barão, I. R. Garcia Jr., V. Pedrazzi, and W. G. Assunção, "Prosthetic platforms in implant dentistry," Journal of Craniofacial Surgery, vol. 22, no. 6, pp. 2327-2331, 2011.

[51] C. Y. Ha, Y. J. Lim, M. J. Kim, and J. H. Choi, “The influence of abutment angulation on screw loosening of implants in the anterior maxilla," The International Journal of Oral \& Maxillofacial Implants, vol. 26, no. 1, pp. 45-55, 2011.

[52] K.-S. Kim, J.-S. Han, and Y.-J. Lim, "Settling of abutments into implants and changes in removal torque in five different implant-abutment connections. Part 1: cyclic loading," The International Journal of Oral \& Maxillofacial Implants, vol. 29, no. 5, pp. 1079-1084, 2014.

[53] B. Pardal-Pelaez and J. Montero, "Preload loss of abutment screws after dynamic fatigue in single implant-supported restorations. A systematic review," Journal of Clinical and Experimental Dentistry, vol. 9, no. 11, pp. e1355-e1361, 2017.

[54] L. Steinebrunner, S. Wolfart, K. Ludwig, and M. Kern, "Implant-abutment interface design affects fatigue and fracture strength of implants," Clinical Oral Implants Research, vol. 19, no. 12, pp. 1276-1284, 2008.

[55] J.-H. Lee, Y.-H. Huh, C.-J. Park, and L.-R. Cho, "Effect of the coronal wall thickness of dental implants on the screw joint stability in the internal implant-abutment connection," The International Journal of Oral \& Maxillofacial Implants, vol. 31, no. 5, pp. 1058-1065, 2016.

[56] J.-H. Lee, W. Lee, Y.-H. Huh, C.-J. Park, and L.-R. Cho, "Impact of intentional overload on joint stability of internal implant-abutment connection system with different diameter," Journal of Prosthodontics, vol. 28, no. 2, pp. e649-e656, 2019.

[57] J.-H. Lee, D.-G. Kim, C.-J. Park, and L.-R. Cho, "Axial displacements in external and internal implant-abutment connection," Clinical Oral Implants Research, vol. 25, no. 2, pp. e83-e89, 2014.

[58] E. I. Weiss, D. Kozak, and M. D. Gross, "Effect of repeated closures on opening torque values in seven abutment-implant systems," The Journal of Prosthetic Dentistry, vol. 84, no. 2, pp. 194-199, 2000.

[59] R. L. Burguete, R. B. Johns, T. King, and E. A. Patterson, "Tightening characteristics for screwed joints in osseointegrated dental implants," The Journal of Prosthetic Dentistry, vol. 71, no. 6, pp. 592-599, 1994.

[60] J. A. Delben, E. A. Gomes, V. A. Barão, and W. G. Assunção, "Evaluation of the effect of retightening and mechanical cycling on preload maintenance of retention screws," The International Journal of Oral \& Maxillofacial Implants, vol. 26, no. 2, pp. 251-256, 2011.
[61] S. C. Kano, P. Binon, G. Bonfante, and D. A. Curtis, "Effect of casting procedures on screw loosening in UCLA-type abutments," Journal of Prosthodontics, vol. 15, no. 2, pp. 77-81, 2006.

[62] L. Jörnéus, T. Jemt, and L. Carlsson, "Loads and designs of screw joints for single crowns supported by osseointegrated implants," The International Journal of Oral \& Maxillofacial Implants, vol. 7, no. 3, pp. 353-359, 1992. 